\title{
BMJ Open Do recent immigrants have similar obstetrical care and perinatal complications as long-term residents? A retrospective exploratory cohort study in Brussels
}

Leila Paquier, ${ }^{1}$ Patricia Barlow, ${ }^{1}$ Marianne Paesmans, ${ }^{2}$ Serge Rozenberg (i) ${ }^{1}$

To cite: Paquier L, Barlow $\mathrm{P}$, Paesmans $\mathrm{M}$, et al. Do recent immigrants have similar obstetrical care and perinatal complications as long-term residents? A retrospective exploratory cohort study in Brussels. BMJ Open 2020;10:e029683. doi:10.1136/ bmjopen-2019-029683

- Prepublication history and additional material for this paper are available online. To view these files, please visit the journal online (http://dx.doi. org/10.1136/bmjopen-2019029683).

Received 07 February 2019 Revised 30 January 2020 Accepted 12 February 2020

D Check for updates

(c) Author(s) (or their employer(s)) 2020. Re-use permitted under CC BY-NC. No commercial re-use. See rights and permissions. Published by BMJ.

${ }^{1}$ Obstetrics and Gynecology, $\mathrm{CHU}$ St Pierre Université Libre de Bruxelles, Brussels, Belgium ${ }^{2}$ Data Center, Institut Jules Bordet, Brussels, Belgium

Correspondence to Dr Serge Rozenberg; Serge_Rozenberg@stpierrebru.be

\section{ABSTRACT}

Purpose Recent immigrants (Rls) face various barriers affecting quality of care. The main research question assessed whether perinatal complications (during pregnancy, labour, delivery and neonatal period) were similar in Rls to those in long-term residents (LTRs). The secondary question assessed whether prenatal and perinatal care was similar in the two groups.

Methods This is a monocentric observational study, carried out in Brussels between November 2016 and March $2017(n=1365)$. We surveyed 892 pregnant women during prenatal consultations and immediate postpartum period in order to identify Rls of less than 3 years $(n=230,25 \%)$ and compared them with LTRs $(n=662)$. Sociodemographic data, baseline health status, prenatal care, obstetrical and neonatal complications were compared between these two groups. Multivariable binary logistic regression was conducted to examine the occurrence of perinatal complications (during pregnancy, labour and delivery, and neonatal period) between Rls and LTRs after adjustment for potential confounders.

Results Rls were living more frequently in precarious conditions. Rls were younger $(p<0.001)$ and had a lower body mass index $(p<0.001)$ than LTRs. Prenatal care was often delayed in Rls, resulting in fewer evaluations during the first trimester $(p<0.001)$. They had a lower prevalence of gestational diabetes mellitus $(p<0.05)$ and less complications during the pregnancy even after adjustment for confounding factors. Similar obstetrical care during labour and delivery occurred. After adjustment for confounding factors, no differences in labour and delivery complications were observed. Although Rls' newborns had a lower umbilical cord blood pH $(<0.05)$, a lower 1 min of life Apgar score $(p<0.01)$ and more frequently required respiratory assistance $(p<0.05)$, no differences in the composite endpoint of neonatal complications were observed. No increase in complications in the Rl group was detected whatever the considered period.

Conclusion Rls had less optimal prenatal care but this did not result in more obstetrical and perinatal complications.

\section{BACKGROUND}

The global health community declared 2019 the year to spur action for achieving universal
Strengths and limitations of this study

- We developed a charity 'Aquarelle' inside the obstetrics and gynaecology department to assist undocumented pregnant immigrants in need.

- We developed a questionnaire to assess whether a patient was a recent immigrant, which was used systematically during interviews of 892 parturients.

- A quarter of the parturients in our study lived in Belgium for less than 3 years and 10\% less than 1 year.

- The language barrier and the absence of medical charts including medical history before the immigration may have resulted in the underdiagnosis of some pathologies in the group of recent immigrants (RIs).

- Another limitation stems from the heterogeneity of both the RI (from a number of different countries) and the reference populations.

health coverage. ${ }^{1}$ Effective universal health coverage implementation relies on building adequate infrastructure, including access to screening, accurate and timely diagnostics. ${ }^{1}$ For several years, an increase in requests for asylum has been seen in Belgium. This is essentially the consequence of world conflicts and economical concerns. ${ }^{2}$ It has been reported that immigrants often encounter linguistic, social, political and economic barriers, resulting in reduced access to health systems, and increased morbidity. ${ }^{3-5}$ Some studies reported a higher prevalence of obstetrical and perinatal complications in immigrant women when compared with native residents. ${ }^{67}$ Additionally, the refugee population is likely more vulnerable. ${ }^{589}$ Few studies have, however, taken into consideration the time of arrival and it is possible that the first years on arrival are associated with even greater fragility. Finally, a process of 


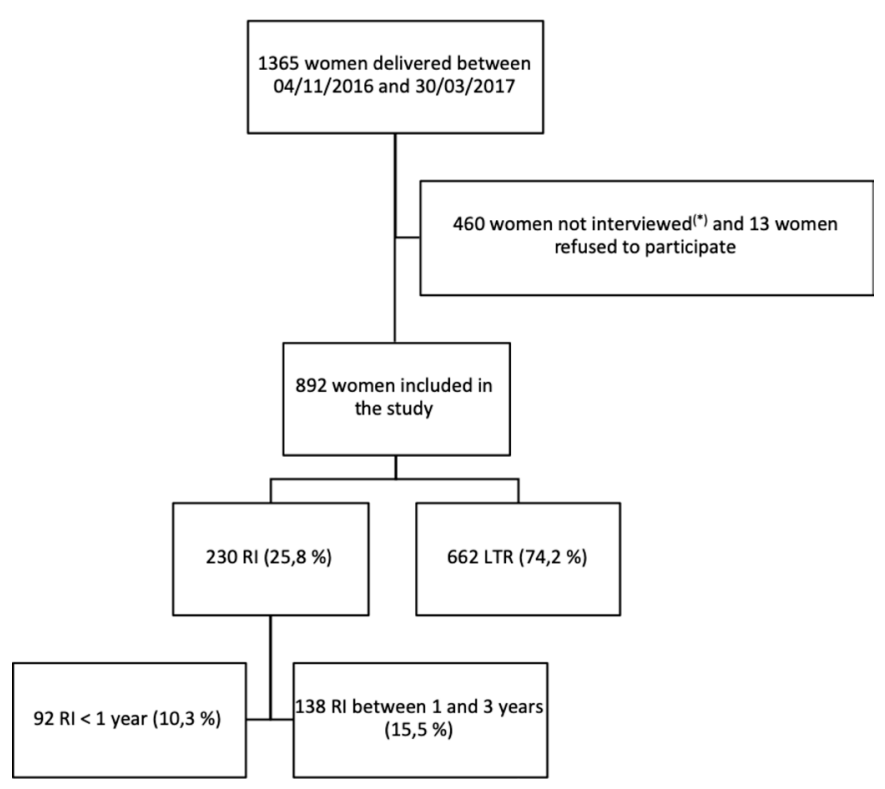

Figure 1 Flow diagram of patients' selection. In total, 1365 women delivered between 4 November 2016 and 30 March 2017, among which 892 (65\%) were included and gave birth to 906 babies (12 twins and 1 triple pregnancy, equally distributed among recent immigrants (RIs) and longterm residents (LTRs)). Eight hundred eighty-eight were interviewed in the immediate postpartum period and four were interviewed at the prenatal consultation. ${ }^{*}$ Those women were not interviewed because of the absence of the principal interviewer.

'acculturation' may occur, which might result in cultural changes and loss of protective factors, such as social or family support network. ${ }^{4}$ This 'acculturation' may therefore lead to the emergence of some new risk factors, such as obesity and addictions that were not present on arrival, and an increased risk of medical complications. ${ }^{10-13}$ The main research question of this study was to assess whether perinatal complications (during pregnancy, labour and delivery, and the neonatal period) were similar in recent immigrants (RIs) to those in long-term residents (LTRs). The secondary question was to assess whether prenatal and perinatal care was similar in RIs as compared with LTRs.

\section{METHODS}

\section{Design and population}

This is a retrospective, exploratory cohort study comparing prenatal and perinatal care as well as perinatal complications (during pregnancy, labour and delivery, and the neonatal period) in RIs and LTRs.

The CHU Saint-Pierre is a university community tertiary hospital, located in downtown Brussels, to which most immigrants or uninsured people who live in the Brussels area are referred for treatment. We developed a charity 'Aquarelle' inside the department of obstetrics and gynaecology. This non-profit association provides medical help, social assistance and material support to undocumented pregnant immigrants in need. ${ }^{14}$ Data from all women who gave birth between 4 November 2016 and 30 March 2017, at the CHU Saint-Pierre were extracted from the prospective database (Medar) that is updated on a daily basis. We developed a questionnaire to assess whether a patient was a RI and if so, since when. We established which patients were RIs, based on the definition of such individuals by the Brussels and Walloon French-speaking regions, that is, foreign nationals who have been in Belgium for less than 3 years before their delivery date, whether they were undocumented immigrants or not. ${ }^{15}$ LTRs were defined as those who were born in or had immigrated to Belgium, over 3 years ago. ${ }^{15}$ Some sociodemographic data were collected using the questionnaire, which was first validated in a pilot study before using it systematically.

During the study period, 1365 women gave birth at the CHU Saint-Pierre. We were able to interview and include 892 women (figure 1). Most (90\%) were interviewed by a final-year medical student who is the first author of this study (LP). The others were either interviewed by colleagues to her or by the head of the obstetric department $(\mathrm{PB})$, who is a coauthor. When interviews occurred, they were conducted systematically and $1 \%$ of patients $(\mathrm{n}=13)$ declined to participate in the study. Inclusion and exclusion criteria are shown in figure 1.

When a major language barrier was encountered, we sought the help of translators. Unfortunately, we did not systematically note how often a translator was needed nor did we evaluate the patients' language skills.

\section{Baseline variables}

The following baseline variables were collected: sociodemographic (age, education, employment, marital status, housing, country of origin, ${ }^{16}$ reasons for migration, 'whether the immigrant can count on someone for support', regular health coverage). Once immigrants, in Belgium, legalise their situation, they may have access to a health coverage and therefore obtain a full access to medical care, while immigrants having a 'refugee status' receive only help in restricted medical situations which is called 'Urgent medical aid' (Aide Médicale Urgente, AMU).${ }^{17}$ Health status was assessed at the first prenatal visit (body mass index (BMI), obesity $\left(\mathrm{BMI} \geq 30.0 \mathrm{~kg} / \mathrm{m}^{2}\right)$, pre-existing diabetes, pre-existing high blood pressure (HBP), infectious diseases (HIV, hepatitis B/C, syphilis), obstetrical data (nulliparity, unusually high multiparity, history of a caesarean section)) .

We categorised the following continuous variable: age (age: $<25,25-34$ and $\geq 35$ years).

Considering that many factors jeopardising healthy status have a low prevalence, we created a composite variable describing the overall patient's health status. Not having a healthy status at the first prenatal visit was defined as the presence of any of the following pathologies: obesity, diabetes, HBP, infectious diseases (HIV, hepatitis $\mathrm{B} / \mathrm{C}$ or syphilis), history of a caesarean section, epilepsy, asthma, heart disease, uterine myomatosis, uterine malformation, genital mutilation. 


\section{Outcomes}

The following outcomes were collected: prenatal care (gestational age at first prenatal consultation, Down syndrome screening, oral glucose tolerance test (OGTT) screening for diabetes, Rhogam administration at any point during the pregnancy or postpartum when required).

Maternal and fetal complications during pregnancy (hypothyroidism, gestational diabetes mellitus, iron deficiency anaemia, gestational hypertension, pre-eclampsia, symptoms of preterm labour, placenta praevia, intrauterine growth retardation (IUGR), macrosomia). Healthcare during labour and delivery (analgesia during labour and for caesarian section, labour induction, vaginal delivery, planned or emergency caesarean section). Maternal and fetal complications during labour and delivery (hypertensive diseases, ${ }^{18}$ placental abruption, postpartum haemorrhage, inflammatory syndrome, failure to progress, severe perineal laceration (D3-D4) (we try to avoid episiotomies, if possible ${ }^{19}$ ), abnormal fetal heart rate (FHR), shoulder dystocia). Neonatal complications (preterm birth, birth weight, Apgar score, umbilical cord blood $\mathrm{pH}$, ventilation need, admission to the neonatal intensive care unit, malformations).

Considering that some complications have a low prevalence, we created composite endpoints: according to whether or not the patients had (1) a presence of major complications during the pregnancy, (2) a presence of complications during labour and delivery, and (3) a presence of complications during the neonatal period.

Composite endpoints:

- Presence of any of the following maternal complications during pregnancy: hypothyroidism, gestational diabetes, iron deficiency anaemia, gestational hypertension, pre-eclampsia, symptoms of preterm labour, placenta praevia, abdominal trauma, urinary tract infection, respiratory infection, chlamydia or gonorrhoea infection, condylomata, genital herpes, malaria, listeriosis, renal colic, gastro-oesophageal reflux, gallstones, thrombocytopenia, threat of late miscarriage, preterm rupture of membranes, uterine cervical incompetence, pregnancy cholestasis, uterine dehiscence, isoimmunisation.

- Presence of any of the following maternal complications during labour and delivery: hypertensive diseases, placental abruption, postpartum haemorrhage, inflammatory syndrome, maternal fever during labour, failure to progress, severe perineal laceration (D3-D4), instrumentation delivery, caesarean, uterine rupture.

- Presence of any of the following neonatal complications: preterm birth, birth weight $(\geq 2.5$ and $\leq 4$ $\mathrm{kg}),<7$ Apgar at 1 and $5 \mathrm{~min}$ of birth, fetal acidosis $(\mathrm{pH}<7)$, artificial ventilation needed, admission to the neonatal intensive care unit, malformations.

\section{Statistical analyses}

The sociodemographical and clinical data were compared using parametric and non-parametric tests. Variables were only analysed for complete cases.

Continuous variables, which are normally distributed, were analysed by t-test and analysis of variance (ANOVA). In case of inequal variances in ANOVA, we used the Games-Howell test. When the continuous variables were not normally distributed, we used a non-parametric test for independent samples to compare the distribution locations (Mann-Whitney test). Categorical variables were evaluated using the $\chi^{2}$ or Fisher's exact test. Multivariable binary logistic regression was carried out to examine the occurrence of perinatal complications (repeated three times according to the period of complications): (1) during pregnancy, (2) during labour and delivery, and (3) during the neonatal period. Rates of occurrence were compared between RIs and LTRs, after adjustment for potential confounders. For sensitivity analyses, we also compared recent immigrants who had been in Belgium for less than 1 year and those who had been in Belgium between 1 and 3 years, as well as LTRs who were born in Belgium and those who immigrated more than 3 years before. The latter groups were again divided into those who had access to regular health coverage and those who had no access to regular health coverage, but did however, benefit from 'Urgent medical aid'.

\section{Sample size}

This work had to be done within a fixed time period with roughly a number of parturients susceptible to be included in the study estimated to be around 900 (on the basis of historical activity of the maternity clinic). We had no specific hypothesis to test and the nature of the planned study was exploratory.

Nevertheless, before deciding to conduct the study, we made very rough assumptions, which were the following: rate of perinatal complications among LTRs about $10 \%$ (without relying on a specific reference), absolute increase of $10 \%$ among RIs to be detected, two-sided type I error of $5 \%$, power of $80 \%$, ratio $1: 1$ (we had no historical data to estimate this ratio). Using these assumptions, we estimated that the required sample size was about 350 .

As the true expected sample size was about 2.5-fold that estimate, we considered that the study was feasible and we did not attempt to conduct any sensitivity calculations to see the impact on the sample size of variations made on the above assumptions.

Due to the exploratory nature of the study, we did not attempt to make adjustments for multiplicity.

\section{Patient and public involvement}

We did not involve patients or the public in the development of the research question, or the design of this study. Patients were systematically invited to answer the questionnaire during and after the delivery. The results will not be disseminated to the interviewed parturients. 
Table 1 Principal maternal sociodemographic data of recent immigrants and long-term residents

\begin{tabular}{|c|c|c|c|}
\hline & $\begin{array}{l}\text { Recent } \\
\text { immigrants }\end{array}$ & $\begin{array}{l}\text { Long-term } \\
\text { residents }\end{array}$ & \multirow[b]{3}{*}{ P value } \\
\hline & $n=230$ & $n=662$ & \\
\hline & $\begin{array}{l}\text { Mean (土SD) } \\
\text { N (\%) }\end{array}$ & $\begin{array}{l}\text { Mean (土SD) } \\
\mathbf{N}(\%)\end{array}$ & \\
\hline $\begin{array}{l}\text { Mean age }( \pm S D) \\
\text { (years) }\end{array}$ & $28( \pm 6)$ & $31( \pm 6)$ & $<0.001$ \\
\hline Education* & $n=227$ & $n=662$ & $<0.01$ \\
\hline None & 23 (10.1\%) & $33(5 \%)$ & \\
\hline $\begin{array}{l}\text { Primary } \\
\text { school }\end{array}$ & $57(25.1 \%)$ & 117 (17.7\%) & \\
\hline $\begin{array}{l}\text { Secondary } \\
\text { school }\end{array}$ & $76(33.5 \%)$ & 245 (37\%) & \\
\hline $\begin{array}{l}\text { Superior } \\
\text { education }\end{array}$ & $71(31.3 \%)$ & 267 (40.3\%) & \\
\hline Unemployed* & $\begin{array}{l}n=227 \\
206(90.7 \%)\end{array}$ & $\begin{array}{l}n=662 \\
372(56.2 \%)\end{array}$ & $<0.001$ \\
\hline Single† & $\begin{array}{l}n=228 \\
23(10.1 \%)\end{array}$ & $\begin{array}{l}n=662 \\
39(5.9 \%)\end{array}$ & $<0.05$ \\
\hline Housing $\ddagger$ & $n=226$ & $n=660$ & $<0.001$ \\
\hline Shelter & $9(4 \%)$ & $9(1.4 \%)$ & \\
\hline $\begin{array}{l}\text { Family } \\
\text { housing }\end{array}$ & 199 (88.1\%) & $638(96.7 \%)$ & \\
\hline With friend & 18 (8\%) & $13(2 \%)$ & \\
\hline $\begin{array}{l}\text { Cannot count on } \\
\text { somebody§ }\end{array}$ & $\begin{array}{l}n=225 \\
204(90.7 \%)\end{array}$ & $\begin{array}{l}n=660 \\
635(96.2 \%)\end{array}$ & $<0.01$ \\
\hline $\begin{array}{l}\text { No regular social } \\
\text { coverage }\end{array}$ & 89 (38.7\%) & 63 (9.5\%) & $<0.001$ \\
\hline
\end{tabular}

${ }^{*}$ Analysis on 889 patients.

†Analysis on 890 patients.

$\ddagger$ Analysis on 886 patients.

$\S$ Analysis on 885 patients.

All data relevant to the study are included in the article or uploaded as online supplementary information.

A strobe checklist is available as online supplementary material (STROBE Statement Leila Paquier.doc).

\section{RESULTS}

The total cohort includes 892 women (230 RIs and 662 LTRs, ie, $65 \%$ of all women who delivered during the study period) (figure 1).

\section{Maternal sociodemographic data and immigration history}

RIs were younger (mean \pm SD: $28 \pm 6$ years vs $31 \pm 6$ years, $\mathrm{p}<0.001)$, were less educated $(35.2 \%$ vs $22.7 \%, \mathrm{p}<0.001)$ and were more often unemployed $(90.7 \%$ vs $56.2 \%$, $\mathrm{p}<0.001$ ) than were LTRs (table 1). RIs had less support from their partner or another person than the LTRs $(p<0.01)$ and were more frequently housed in shelters or with acquaintances $(\mathrm{p}<0.001)$ (table 1$)$. One hundred fourty-one $(61.3 \%)$ RIs had obtained regular health coverage, whereas $89(38.7 \%)$ benefitted from 'Urgent medical aid (AMU)' (table 1). A third of LTRs (32.9\%) were Belgian natives and two thirds $(67.1 \%)$ of the LTRs were not born in Belgium but had been living in Belgium for more than 3 years. Immigrant patients came from 97 different countries. Most of the RIs came from subSaharan Africa (27.8\%), the Maghreb (26.5\%), North and West Asia and the Middle East (18.3\%). The main reasons why they immigrated were family reunification, economic concerns $(55.6 \%)$ and fleeing armed conflicts $(13.9 \%)$ (online supplementary table S1).

\section{Baseline maternal health status}

RIs had lower BMIs, were less obese $(10.4 \%$ vs $19 \%$, $\mathrm{p}<0.01)$ and were more often nulliparous $(53 \%$ vs $34 \%$, $\mathrm{p}<0.001$ ), but there were no other differences concerning their baseline health status. Respectively, 33\% and 38.5\% of RIs and LTRs were considered not having a healthy status at first prenatal visit (as a composite endpoint) (NS) (online supplementary table S2).

\section{Maternal prenatal care}

RIs had, on average, their first prenatal consultation 1 week later than did LTRs (median 10 weeks vs 9 weeks, $\mathrm{p}<0.001)$ and more often during the second trimester $(19.3 \%$ vs $11.2 \%)$ and third trimester or had no care at all $(12.7 \%$ vs $0.5 \%)$ than LTRs. Fewer RIs underwent a screening for Down syndrome $(\mathrm{p}<0.001)$ (table 2$)$.

\section{Obstetrical complications during pregnancy}

The prevalence of gestational diabetes was lower among RIs than among LTRs ( $14.3 \%$ vs $20.7 \%, \mathrm{p}<0.05)$ (table 3 ). There were no other differences in prevalence of other maternal pathologies between the two populations. There was a lower prevalence of newborn babies with macrosomia among RIs as compared with LTRs $(5.5 \%$ vs $10.8 \%, \mathrm{p}<0.05)$ but the proportion of newborns with IUGR was similar.

Overall, in univariate analysis, RIs had fewer complications rates during pregnancy (composite endpoint) than had LTRs $(41.7 \%$ vs $53.8 \%, p<0.01$ ) (table 3 ).

This result remained significant after fitting the data using a multivariable binary logistic regression, with more complications during pregnancy for a LTR (OR 1.59 (95\% CI 1.17 to 2.16), $\mathrm{p}<0.01$ ), after adjustment for health coverage, age, nulliparity and not having a healthy status at the first prenatal visit (composite variable), the last one being the only remaining significant adjustment (table 4).

\section{Obstetrical care and complications during labour and delivery}

The proportion of RIs and LTRs who required analgesia during labour induction, a vacuum vaginal extraction or a caesarean section were similar (online supplementary table S3).

The prevalence of hypertensive disease, placental abruption and postpartum haemorrhage was similar in both populations. However, RIs had more inflammatory syndromes $(4.3 \%$ vs $1.7 \%, \mathrm{p}<0.05)$, more 'failure to 
Table 2 Prenatal care of recent immigrants and long-term residents

\begin{tabular}{|c|c|c|c|}
\hline & $\begin{array}{l}\text { Recent } \\
\text { immigrants }\end{array}$ & $\begin{array}{l}\text { Long-term } \\
\text { residents }\end{array}$ & \\
\hline & $\begin{array}{l}n=230 \\
\text { Median }\left(P_{25}-\right. \\
\left.P_{75}\right) \mathbf{N}(\%)\end{array}$ & $\begin{array}{l}n=662 \\
\text { Median }\left(P_{25}-\right. \\
\left.P_{75}\right) N(\%)\end{array}$ & $P$ value \\
\hline $\begin{array}{l}\text { Median } \\
\text { gestational age } \\
\text { at first prenatal } \\
\text { consultation (WA)* }\end{array}$ & $10(8-18)$ & $9(7-11)$ & $<0.001$ \\
\hline First trimester & 144 (67.9\%) & 545 (88.3\%) & \\
\hline $\begin{array}{l}\text { Second } \\
\text { trimester }\end{array}$ & 41 (19.3\%) & 69 (11.2\%) & $<0.001$ \\
\hline $\begin{array}{l}\text { Third trimester } \\
\text { or no care }\end{array}$ & 27 (12.7\%) & $3(0.5 \%)$ & \\
\hline $\begin{array}{l}\text { Down } \\
\text { syndrome } \\
\text { screeningt }\end{array}$ & $n=226$ & $n=646$ & $<0.001$ \\
\hline $\begin{array}{l}\text { Test first } \\
\text { trimester }\end{array}$ & 105 (46.4\%) & 370 (57.2\%) & \\
\hline $\begin{array}{l}\text { Test second } \\
\text { trimester }\end{array}$ & $9(3.9 \%)$ & 26 (4.1\%) & \\
\hline Too late & 65 (28.8\%) & 70 (10.8\%) & \\
\hline Refusal & 30 (13.3\%) & $102(15.8 \%)$ & \\
\hline Unknown & 17 (7.5\%) & 78 (12.1\%) & \\
\hline OGTT‡ & $n=176$ & $n=538$ & NS \\
\hline Done & $174(98.8 \%)$ & $524(97.4 \%)$ & \\
\hline Unknown & $2(1.1 \%)$ & $14(2.6 \%)$ & \\
\hline $\begin{array}{l}\text { No Rhogam } \\
\text { received§ }\end{array}$ & $\begin{array}{l}n=25 \\
5(20 \%)\end{array}$ & $\begin{array}{l}n=67 \\
16(23.9 \%)\end{array}$ & NS \\
\hline
\end{tabular}

${ }^{*}$ Analysis on 829 patients.

†Analysis 872 patients.

$\ddagger$ Analysis 714 patients.

$\S$ Analysis after exclusion of women with Rhesus group+, $\mathrm{n}=92$.

NS, not statistically significant; OGTT, oral glucose tolerance test;

WA, weeks of amenorrhoea.

progress' $(37.5 \%$ vs $29 \%, \mathrm{p}<0.05)$ and more severe perineal lacerations $(7.9 \%$ vs $1.3 \%, \mathrm{p}<0.001)$ compared with LTRs (table 5). Abnormal fetal heart rates were more frequently observed on monitors among RIs than among LTRs $(32.5 \%$ vs $21.7 \%, \mathrm{p}<0.001)$ but there were no differences in shoulder dystocia (table 5 ).

Overall, RIs had more complications (composite endpoint) during labour and delivery compared with LTRs $(63.5 \%$ vs $54.8 \%, \mathrm{p}<0.05)$ (table 5 ).

However, after adjustment for age, nulliparity, health coverage and not having a healthy status at the first prenatal visit (composite variable), these differences were no longer detectable during labour and delivery (composite endpoint) (OR 0.82 (95\% CI 0.57 to 1.17), NS) (table 6).

\section{Neonatal complications}

There were no differences in the proportions of neonatal complications due to preterm birth rates or small weight
Table 3 Maternal and fetal complications during pregnancy of recent immigrants and long-term residents

\begin{tabular}{|c|c|c|c|}
\hline & $\begin{array}{l}\text { Recent } \\
\text { immigrants }\end{array}$ & $\begin{array}{l}\text { Long-term } \\
\text { residents }\end{array}$ & \\
\hline & N (\%) & $\mathbf{N}(\%)$ & P value \\
\hline Maternal & $n=230$ & $n=662$ & \\
\hline Hypothyroidism & $15(6.5 \%)$ & 59 (8.9\%) & NS \\
\hline $\begin{array}{l}\text { Gestational } \\
\text { diabetes }\end{array}$ & $33(14.3 \%)$ & 137 (20.7\%) & $<0.05$ \\
\hline Anaemia & $42(18.3 \%)$ & 113 (17.1\%) & NS \\
\hline $\begin{array}{l}\text { Gestational } \\
\text { hypertension }\end{array}$ & $1(0.4 \%)$ & $10(1.5 \%)$ & NS \\
\hline Pre-eclampsia & $5(2.2 \%)$ & $23(3.5 \%)$ & NS \\
\hline $\begin{array}{l}\text { Symptoms of } \\
\text { preterm labour }\end{array}$ & $6(2.6 \%)$ & $24(3.6 \%)$ & NS \\
\hline Placenta praevia & $4(1.7 \%)$ & $8(1.2 \%)$ & NS \\
\hline $\begin{array}{l}\text { No. of women with } \\
\text { complications }\end{array}$ & $96(41.7 \%)$ & $356(53.8 \%)$ & $<0.01$ \\
\hline Fetal & $n=237$ & $n=669$ & \\
\hline IUGR & 7 (3\%) & $11(1.6 \%)$ & NS \\
\hline Macrosomia & $13(5.5 \%)$ & 72 (10.8\%) & $<0.05$ \\
\hline
\end{tabular}

*As a composite endpoint for women with complications during pregnancy.

IUGR, intrauterine growth retardation; NS, not statistically significant.

for gestational age $(<2.5 \mathrm{~kg})$. RIs' newborns presented more fetal distress (low Apgar score at $1 \mathrm{~min})(13.9 \%$ vs $7.8 \%, \mathrm{p}<0.01)$, lower umbilical cord blood $\mathrm{pH}(7.27 \pm 0.08$ vs $7.29 \pm 0.08, \mathrm{p}<0.05)$ and required more breathing assistance $(11.8 \%$ vs $6.6 \%, \mathrm{p}<0.05)$ than the newborns of LTRs (table 5 ). We observed that 55 newborns $(23 \%)$ of the RIs and $108(16 \%)$ of the LTRs needed to be transferred to the neonatal intensive care unit $(\mathrm{p}<0.05)($ table 5$)$. There was no difference in malformation rates.

Overall, the number of newborns with complications (composite endpoint) was comparable in the two groups.

We failed to identify confounders among the considered covariables (age, health coverage, not having a healthy status at the first prenatal visit and nulliparity) and so we

Table 4 Multivariable binary logistic regression for complications during pregnancy between recent immigrants and long-term residents

\begin{tabular}{llll}
\hline & OR & $95 \%$ Cl & P value \\
\hline $\begin{array}{l}\text { Main covariable } \\
\begin{array}{l}\text { Long-term residents } \\
\text { Adjustment covariable* }\end{array}\end{array}$ & 1.59 & 1.17 to 2.16 & $<0.01$ \\
$\begin{array}{c}\text { No healthy status at } \\
\text { first prenatal visit }\end{array}$ & 1.57 & 1.19 to 2.07 & $<0.01$ \\
\hline
\end{tabular}

*Age, social coverage and nulliparity were associated with the occurrence of complications in univariate analysis but were no longer significant after adjustment for healthy status and were removed from the model. 
Table 5 Obstetrical pathologies during labour and delivery, and neonatal complications among recent immigrants and long-term residents

\begin{tabular}{|c|c|c|c|}
\hline & $\begin{array}{l}\text { Recent } \\
\text { immigrants }\end{array}$ & $\begin{array}{l}\text { Long-term } \\
\text { residents }\end{array}$ & \\
\hline & $\begin{array}{l}\mathbf{N}(\%) \\
\text { Median }\left(\mathbf{P}_{25}-\right. \\
\left.\mathbf{P}_{75}\right) \\
\text { Mean (士SD) }\end{array}$ & $\begin{array}{l}\mathbf{N}(\%) \\
\text { Median }\left(\mathbf{P}_{25}-\right. \\
\left.\mathbf{P}_{75}\right) \\
\text { Mean ( }(\mathrm{SD})\end{array}$ & $P$ value \\
\hline Maternal & $n=230$ & $n=662$ & \\
\hline Hypertensive disease & $2(0.9 \%)$ & $12(1.8 \%)$ & NS \\
\hline Abruptio placental & $3(1.3 \%)$ & $3(0.5 \%)$ & NS \\
\hline $\begin{array}{l}\text { Postpartum } \\
\text { haemorrhage }\end{array}$ & 55 (23.9\%) & $134(20.2 \%)$ & NS \\
\hline $\begin{array}{l}\text { Inflammatory } \\
\text { syndrome }\end{array}$ & $10(4.3 \%)$ & $11(1.7 \%)$ & $<0.05$ \\
\hline Failure to progress ${ }^{*}$ & $\begin{array}{l}n=176 \\
66(37.5 \%)\end{array}$ & $\begin{array}{l}n=507 \\
147(29 \%)\end{array}$ & $<0.05$ \\
\hline $\begin{array}{l}\text { Severe perineal } \\
\text { laceration (D3-D4) } †\end{array}$ & $\begin{array}{l}n=177 \\
14(7.9 \%)\end{array}$ & $\begin{array}{l}n=520 \\
7(1.3 \%)\end{array}$ & $<0.001$ \\
\hline Caesarean & $53(23 \%)$ & $142(21.5 \%)$ & NS \\
\hline $\begin{array}{l}\text { No. of women with } \\
\text { complications } \ddagger\end{array}$ & $146(63.5 \%)$ & $363(54.8 \%)$ & $<0.05$ \\
\hline Fetal & $\mathrm{n}=237$ & $n=669$ & \\
\hline Abnormal FHR & 77 (32.5\%) & $145(21.7 \%)$ & $<0.01$ \\
\hline Shoulder dystocia & $9(3.8 \%)$ & 22 (3.3\%) & NS \\
\hline Median GA (days) & 278 (271-286) & 278 (270-284) & NS \\
\hline $\begin{array}{l}\text { Preterm birth }(<37 \\
\text { WGA) }\end{array}$ & $14(5.9 \%)$ & 53 (7.9\%) & NS \\
\hline Weight of NB (SD) (kg) & $3.2( \pm 0.6)$ & $3.3( \pm 0.6)$ & NS \\
\hline Weight $<2.5 \mathrm{~kg}$ & $21(8.9 \%)$ & $45(6.7 \%)$ & NS \\
\hline Weight>4 kg & $16(6.8 \%)$ & $58(8.7 \%)$ & NS \\
\hline Apgar score & $\mathrm{n}=237$ & $n=666$ & \\
\hline Apgar $<7$ at $1 \mathrm{~min}$ & $33(13.9 \%)$ & $52(7.8 \%)$ & $<0.01$ \\
\hline Apgar $<7$ at $5 \mathrm{~min}$ & $11(4.6 \%)$ & $20(3 \%)$ & NS \\
\hline Umbilical cord blood pH & $7.27 \pm 0.08$ & $7.29 \pm 0.08$ & $<0.05$ \\
\hline Ventilation needed & $28(11.8 \%)$ & $44(6.6 \%)$ & $<0.05$ \\
\hline $\mathrm{NIC}$ & $55(23.2 \%)$ & $108(16.1 \%)$ & $<0.05$ \\
\hline Malformations & $5(2.1 \%)$ & $14(2.1 \%)$ & NS \\
\hline $\begin{array}{l}\text { No. of NB§ with } \\
\text { complications }\end{array}$ & $70(29.5 \%)$ & $186(27.8 \%)$ & NS \\
\hline
\end{tabular}

*Analysis after exclusion of women with planned caesarean $(n=683)$. $\dagger$ Analysis after exclusion of women with caesarean delivery $(n=697)$. $\ddagger$ As a composite endpoint for women with complications during labour and delivery.

$\S A$ a composite endpoint for newborns with complications.

FHR, fetal heart rate; GA, gestational age at birth; NB, newborn; NS, not statistically significant.

did not adjust the main variable in multivariable analyses for the complications during the neonatal period.

The results of the sensitivity analyses are available in the online supplementary material tables S4-S13.

\section{DISCUSSION}

The aim of this study was to determine prenatal and perinatal care, as well as perinatal complications (during
Table 6 Multivariable binary logistic regression for complications during labour and delivery between recent immigrants and long-term residents (LTRs)

\begin{tabular}{llll}
\hline & OR & $95 \% \mathbf{C l}$ & P value \\
\hline $\begin{array}{l}\text { Main covariable } \\
\text { LTRs }\end{array}$ & 0.82 & 0.57 to 1.17 & NS \\
$\begin{array}{l}\text { Adjustment covariable* } \\
\text { No health coverage }\end{array}$ & 1.58 & 1.07 to 2.32 & $<0.05$ \\
$\begin{array}{l}\text { No healthy status at } \\
\text { the first prenatal visit }\end{array}$ & 2.59 & 1.90 to 3.53 & $<0.001$ \\
$\quad$ Nulliparity & 3.48 & 2.53 to 4.79 & $<0.001$ \\
\hline
\end{tabular}

${ }^{*}$ Age was associated with the occurrence of complications during labour and delivery in univariate analysis but was no longer significant after adjustment for the three other adjustment covariables and was removed from the model.

NS, not statistically significant

pregnancy, labour and delivery, and the neonatal period), in RIs compared with LTRs. The first noteworthy finding in this study was the large number of RIs: a quarter of the parturients have lived in Belgium for less than 3 years and $10 \%$ less than 1 year. Prenatal care was often delayed in RIs, resulting in fewer evaluations during the first trimester, but similar obstetrical care during labour and delivery occurred. Considering composite endpoints, fewer RIs had complications during pregnancy than LTRs, but the complications occurring during labour and delivery and the number of newborns with complications were comparable in the two groups.

Being a RI sometimes increases the risk of suffering from certain health issues. They may live in isolation, in precarious conditions, encounter administrative, financial or linguistic barriers which leads to reduced access to optimal healthcare. ${ }^{3}$ Some studies have reported an excess of obstetrical complications among migrant patients. ${ }^{6720}$ We observed that pregnant RIs were younger and more often nulliparous confirming observations made by Erenel $e t a l,{ }^{21}$ but not by others. ${ }^{6}$

The RIs in this study more frequently lived in insecure conditions, were less educated and were more likely to be unemployed than the LTRs. However, immigrants' profiles vary between countries depending on government's immigration policies. ${ }^{22}$ We also noted that about $15 \%$ of recent immigrants migrated because of current conflicts, such as the war in Syria. Pregnant RIs were more often without a partner and living in difficult social isolation. This is even more striking as the reference population of LTRs at the CHU Saint-Pierre is already a more precarious, younger population with a higher proportion of comorbidities, compared with the general population of parturient women in Belgium or the Brussels region.

Although RIs have a worse socioeconomic profile, the global maternal health situation of the two groups was comparable for the composite variable, but the RIs were younger and were therefore less at risk for some pathologies.

The medical care of RIs often begins later during pregnancy and is sometimes of lower quality than that 
of LTRs. ${ }^{4-6} 212324$ We found this to be even more the case for a subgroup of pregnant women who had been immigrants for less than a year (results in the online supplementary material). Language barrier, the lack of information about access to healthcare, the obstacles related to administrative procedures, the fear of being identified as an illegal resident and then deported may all lead to suboptimal prenatal care. ${ }^{3420212526}$ The work of the charity, 'Aquarelle', which provides yearly medical help, social assistance and material support to around 500 undocumented pregnant immigrants in need, may have improved partially the prenatal care to RIs. ${ }^{14}$ Although we observed, for instance, fewer prenatal tests for Down syndrome among RIs, we did not observe a difference in OGTT, which is performed later in pregnancy. Moreover, the prevalence of gestational diabetes was lower among RIs than among LTRs. This is probably the case because immigrants are generally younger and less likely to be obese than are LTRs. RIs had surprisingly fewer complications during pregnancy. We hypothesised that RIs had not yet turned to unhealthy diets, which often occurs in precarious patient, thereby increasing the risk of obesity and diabetes. ${ }^{10}$ These results are somewhat also in contradiction with other publications such as the meta-analysis conducted by Gagnon $e t a l^{27}$ who reported an increased risk of gestational diabetes among migrant women, but these authors also observed a marked heterogeneity between studies. Moreover, the reference group in the study by Gagnon $e t a l^{27}$ is very different from the present study, thus direct comparison cannot be made.

Although some authors reported, in their series, less epidural analgesia for migrant women during labour and delivery, this was not the case in ours. ${ }^{28}$

We observed no differences in terms of labour induction or caesarean section rates between RIs and LTRs, whereas inconsistent results have been published by other authors, some reporting higher and others reporting lower rates of caesarean sections in RI populations. ${ }^{22} 232930$ A certain number of obstetrical complications such as failure to progress labour, inflammatory syndrome during labour, fetal distress and severe perineal lacerations were more prevalent among RIs. Overall, this group had more complications during labour and delivery. Nevertheless, this difference disappeared after adjusting for confounding variables such as age, nulliparity, not having a healthy status at first prenatal visit and health coverage.

At delivery, RIs' newborns often had lower Apgar scores at $1 \mathrm{~min}$, a lower umbilical cord $\mathrm{pH}$ and more frequently required mechanical ventilation than did those of LTRs. Similarly, we observed more admissions of RIs' newborns than of LTRs' newborns to the neonatal intensive care unit. However, globally, the composite neonatal endpoint was comparable in the two groups.

This study contains several possible limitations and biases. First, we cannot evaluate the external representatively of the results. Indeed, this study was conducted in Brussels, in one centre only, but which is the maternity with the highest rate of immigrants in Belgium. We collected prenatal and obstetrical data daily and validated them every weekday on a structured, computerised chart, but some patients had received prenatal care elsewhere, which resulted in incomplete or missing data and may have led to underdiagnosing. Unfortunately, this obstetric programme was designed 20 years ago and does not use ICD codes, which would have been preferable for comparing studies and carrying out systematic reviews. Due to the language barrier and the absence of medical charts, RIs may have more often omitted past pathologies, which may be associated with a higher risk of underdiagnosis. Similarly, the inability to collect data about other barriers to access to care may have also resulted in underdiagnosis. Moreover, we did not manage to interview all of the patients. Another limitation stems from the heterogeneity of both the recent immigrant (from a number of different countries) and the reference populations. We must also specify that our LTR population includes a proportion of women from an immigrant background $(67.2 \%)$, which is much greater than what is seen elsewhere in Belgium. We hypothesise that this, on the other hand, may have obscured some differences that may have existed if we had compared RIs with LTRs that included only native residents. The results for other outcomes than perinatal complications (our main research question) should be interpreted with caution in this exploratory study, since we may lack statistical power. Calculating our study power with revised assumptions according to our results, we find that our sample size was still adequate for a statistical power estimated around $75 \%$ (but we lacked power for $80 \%$ or $90 \%$ ) (with a two-sided type I error of $5 \%$, ratio $3: 1, \mathrm{n}=900)$ to detect a perinatal complication rate of 55\% among LTRs (during pregnancy and during labour and delivery) and an absolute rate increase of $10 \%$ among RIs.

In conclusion, in this study, we found that one out of four patients who delivered in one of the largest public hospitals in Brussels had immigrated within the previous 3 years. Most of these women live in precarious socioeconomic conditions. A delay in prenatal care occurred often during the first trimester, resulting in lower screening rates for Down syndrome. On the other hand, these women are generally in good health and few differences are observed in terms of perinatal complications between them and LTRs. This may have further wider important implications since some recent studies reported that protecting unauthorised immigrant mothers improves their children's further development and mental health. ${ }^{31}$

Twitter Serge Rozenberg @Rozenberg

Contributors LP, PB and SR were involved in the project development. LP and PB were involved in the data collection. LP interviewed the patients and analysed the data with the help of SR. LP wrote the first manuscript draft. MP reviewed the statistical analyses. All coauthors contributed to editing of the manuscript.

Funding The authors have not declared a specific grant for this research from any funding agency in the public, commercial or not-for-profit sectors.

Competing interests None declared. 
Patient consent for publication Not required.

Ethics approval This study was approved by the ethical committee of the CHU Saint-Pierre (Agreement No.: 0.M. 007) hospital (Protocol No: B076201630187).

Provenance and peer review Not commissioned; externally peer reviewed.

Data availability statement Data are available on reasonable request.

Open access This is an open access article distributed in accordance with the Creative Commons Attribution Non Commercial (CC BY-NC 4.0) license, which permits others to distribute, remix, adapt, build upon this work non-commercially, and license their derivative works on different terms, provided the original work is properly cited, appropriate credit is given, any changes made indicated, and the use is non-commercial. See: http://creativecommons.org/licenses/by-nc/4.0/.

ORCID iD

Serge Rozenberg http://orcid.org/0000-0002-6482-0070

\section{REFERENCES}

1 The Lancet. Ensuring and measuring universality in UHC. Lancet 2019;393:1.

2 Myria. Available: https://www.myria.be/files/Migration2016fichesrésumés.pdf

3 SantiagoM da CF, Figueiredo MH. Immigrant women's perspective on prenatal and postpartum care: systematic review. J Immigr Minor Health 2015;17:276-84.

4 Almeida LM, Caldas J, Ayres-de-Campos D, et al. Maternal healthcare in migrants: a systematic review. Matern Child Health J 2013;17:1346-54.

5 Chu DM, Aagaard J, Levitt R, et al. Cohort analysis of immigrant rhetoric on timely and regular access of prenatal care. Obstet Gynecol 2019;133:117-28.

6 Almeida LM, Santos CC, Caldas JP, et al. Obstetric care in a migrant population with free access to health care. Int J Gynaecol Obstet 2014;126:244-7.

7 Bakken KS, Skjeldal OH, Stray-Pedersen B. Higher risk for adverse obstetric outcomes among immigrants of African and Asian descent: a comparison study at a low-risk maternity hospital in Norway. Birth 2015:42:132-40.

8 Bakken KS, Skjeldal OH, Stray-Pedersen B. Immigrants from conflict-zone countries: an observational comparison study of obstetric outcomes in a low-risk maternity ward in Norway. BMC Pregnancy Childbirth 2015;15:163.

9 Gibson-Helm M, Teede H, Block A, et al. Maternal health and pregnancy outcomes among women of refugee background from African countries: a retrospective, observational study in Australia. BMC Pregnancy Childbirth 2014;14:392.

10 Goel MS, McCarthy EP, Phillips RS, et al. Obesity among US immigrant subgroups by duration of residence. JAMA 2004;292:2860-7.

11 Choi S, Rankin S, Stewart A, et al. Effects of acculturation on smoking behavior in Asian Americans: a meta-analysis. J Cardiovasc Nurs 2008;23:67-73.

12 Zlot Al, Jackson DJ, Korenbrot C. Association of acculturation with cesarean section among Latinas. Matern Child Health J 2005;9:11-20.
13 Urquia ML, Frank JW, Moineddin R, et al. Immigrants' duration of residence and adverse birth outcomes: a population-based study. BJOG 2010;117:591-601.

14 Aquarelle ASBL : Bien-être, c'est d'abord bien naître. Available: https://www.aquarelle-bru.be [Accessed 25 Jun 2019].

15 Accueil des primo-arrivants Bruxelles et en Wallonie: vous avez DIT obligation? Available: https://www.cire.be/wp-content/uploads/2015/ 12/20151222-analyse-parcours-accueil-obligation.pdf

16 Leeuw V V, Leroy C, Zhang WH, et al. Données périnatales en région bruxelloise Année 2014. Centre d'Epidémiologie Périnatale 2016.

17 Medimmigrant, 2019. Available: https://www.medimmigrant.be/ [Accessed 17 Nov 2019].

18 Cohen J, Vaiman D, Sibai BM, et al. Blood pressure changes during the first stage of labor and for the prediction of early postpartum preeclampsia: a prospective study. Eur J Obstet Gynecol Reprod Biol 2015;184:103-7.

19 Amorim MM, Coutinho IC, Melo I, et al. Selective episiotomy vs. implementation of a non-episiotomy protocol: a randomized clinical trial. Reprod Health 2017; 14:55.

20 Barlow P, Haumont D, Degueldre M. [Obstetrical and perinatal outcome of patients not covered by medical insurance]. Rev Med Brux 1994;15:366-70.

21 Erenel H, Aydogan Mathyk B, Sal V, et al. Clinical characteristics and pregnancy outcomes of Syrian refugees: a case-control study in a tertiary care hospital in Istanbul, Turkey. Arch Gynecol Obstet 2017;295:45-50.

22 Mumtaz Z, O'Brien B, Higginbottom G. Navigating maternity health care: a survey of the Canadian prairie newcomer experience. $B M C$ Pregnancy Childbirth 2014;14:4

23 Oberaigner W, Leitner $\mathrm{H}$, Oberaigner $\mathrm{K}$, et al. Migrants and obstetrics in Austria--applying a new questionnaire shows differences in obstetric care and outcome. Wien Klin Wochenschr 2013;125:34-40.

24 Kentoffio K, Berkowitz SA, Atlas SJ, et al. Use of maternal health services: comparing refugee, immigrant and US-born populations. Matern Child Health J 2016;20:2494-501.

25 Small R, Roth C, Raval M, et al. Immigrant and non-immigrant women's experiences of maternity care: a systematic and comparative review of studies in five countries. BMC Pregnancy Childbirth 2014;14:152.

26 Higginbottom GMA, Morgan M, Alexandre M, et al. Immigrant women's experiences of maternity-care services in Canada: a systematic review using a narrative synthesis. Syst Rev 2015;4:13-17.

27 Gagnon AJ, McDermott S, Rigol-Chachamovich J, et al. International migration and gestational diabetes mellitus: a systematic review of the literature and meta-analysis: migration and gestational diabetes mellitus. Paediatr Perinat Epidemiol 2011;25:575-92.

28 Jiménez-Puente A, Benítez-Parejo N, Del Diego-Salas J, et al. Ethnic differences in the use of intrapartum epidural analgesia. BMC Health Serv Res 2012;12:207.

29 David M, Borde T, Brenne S, et al. Caesarean section frequency among immigrants, second- and third-generation women, and Non-Immigrants: prospective study in Berlin/Germany. PLoS One 2015;10:e0127489.

30 Malin M, Gissler M. Maternal care and birth outcomes among ethnic minority women in Finland. BMC Public Health 2009;9:84.

31 Hainmueller J, Lawrence D, Martén L, et al. Protecting unauthorized immigrant mothers improves their children's mental health. Science 2017;357:1041-4. 